\title{
DUBLINERS OR THE FEELING OF FRUSTRATION
}

\author{
Francisco Josẻ Hernández Mata
}

\begin{abstract}
"Dubliners or the Feeling of Frustration", considers diverse frustrations suffered by the different characters in James Joyce's Dubliners.

The article considers the internal lives of the characters, where their minds struggle and react. This determines their interactions and brings them frustrations on the level of their emotions, sexuality and self-esteem, up to a point where a part of their inner selves become nullified or submerged in a state of inferiority as a result of the direct action of their fellow creatures.
\end{abstract}

\section{DUBLINESES O EL SENTIMIENTO DE LA FRUSTRACION}

\section{Francisco José Hernández Mata}

Ellsworth Mason y Richard Ellmann, en su introducción al libro James Joyce: escritos críticos, afirman que James Joyce le dio a la frase que dice así: "debemos aceptar a los hombres y mujeres tal como los encontramos en el mundo real", una validez plena en sus novelas ${ }^{1}$. Esto es aplicable a toda la obra de Joyce, en especial a Dublineses, que es una serie de quince cuentos cortos. Estas historias, en apariencia independientes, tienen una relación estrecha, y la mayor parte de los personajes fueron creados a semejanza de personas que el autor conoció, así como a partir de la observación de numerosos hechos de sus vidas, sobre los que Joyce tejió la trama de estas historias. A los protagonistas el autor los colocó en un ambiente real, la ciudad de Dublín a finales del siglo $X I X$ y principios de $X X$, $y$ allí sufren un cambio radical: la frustración observable en todos los niveles de la vida interior. $\mathrm{Si}$ al hacer un estudio penetramos en la intimidad psicológica de los personajes, encontramos una serie de ricos elementos que ilustran bien este ambiente de desasosiego y ansiedad. En relación con esto, Raúl H. Castagnino nos aclara la idea cuando dice:

El carácter es el nácleo íntimo, intransferible, que constituye la individualidad: es una resultante en la cual inter- vienen entre muchos factores, la herencia, el temperamento, la sensibilidad, las creencias, la educación, el medio ... pero sobre todo la voluntad ${ }^{2}$.

Precisamente en este mundo interno de los protagonistas, es donde nos percatamos cómo sus mentes luchan y reaccionan. Esto determina su interacción, y de allí nacen frustraciones en el ámbito interno de cada ser; sus emociones, su sexualidad y su autoestima. En ciertos aspectos la modificación alcanza tal punto que su yo interno se aniquila llevándolos a un estadio de inferioridad como resultante directa de la acción de sus semejantes.

El objetivo de este artículo es considerar los diferentes niveles de frustración y tormentos internos previamente mencionados, pero teniendo en cuenta lo que dijo André Gide: tout choix implique une élimination, para así tomar los casos más relevantes a lo largo de todo el libro y estudiarlos en crescendo.

En términos psicológicos, las emociones se encuentran ligadas a las raíces más profundas, ansias $y$ deseos de un individuo en general, y cada vez que algo interfiere con lo que anhela, su mente responde con ansiedad conduciéndolo a una frustración. En este estado de emociones tenemos un primer caso en el cuento "Dos galanes" 3 con el personaje de Lenehan, quien tiene 29 años y pronto tendrá 30 . Florence $\mathrm{L}$. Walzl lo enmarca dentro de una adulescentia ${ }^{4}$, e indica que el personaje a veces se identifica como a un alter ego del Joyce que se hubiera quedado en Irlanda ${ }^{5}$. Lenehan y su 
amigo Corley son dos camaradas que viven de acuerdo a un código de honor no muy ortodoxo: la vida fácil, disfrute de los placeres de la carne y de aprovechamiento de mujeres y la obtención de dinero que mana de ellas. Este código de honor inquieta a Joyce, quien se lo menciona a su editor, Mr. Grant Richards, al contrastar los valores de sus personajes con la idea de caballerosidad que se encuentra en el viejo Dumas ${ }^{6}$

Ambos personajes [Corley y Lenehan] a pesar de tener más o menos la misma edad son bastante diferentes. Corley "hace alarde del poder que tiene sobre una sirvientilla que lo ama"7 y eclipsa a su amigo Lenehan. Corley se percata de que no ha tenido mucho éxito con las mujeres de buena clase, por lo tanto, debe de aprovecharse de las de condición social baja, especialmente de las domésticas de más baja categoría, conocidas como slavies (quienes hacían cualquier labor, en comparación con otras de mejor statu, tales como las sirvientas para el primer piso, etc) y que tenían una renta anual de $£ 6$ o $£ 7 .{ }^{8}$ Por otra parte, Lenehan, al pensar en el amorío de Corley con la sirvientilla, lo invade un sentimiento de vacío e impotencia. Directa y llanamente admite su frustración emocional, y acepta que "la experiencia lo [ha] llenado de amargura contra todo y contra todos. Pero no lo [ha] abandonado la esperanza". $Y$ es mås, considera que "quizá todavía podría acomodarse en un rincón y vivir feliz, con tal.de que encontrara una muchacha buena y simple que tuviera lo suyo"9. Aún cuando deja un portillo abierto a la esperanza, es posible que no haga nada, ya que él, como Corley, continuarán en su statu quo, y aprovechándose de las mujeres en todo aspecto. Al respecto, Zack Bowen afirma que:

$\mathrm{El}$ interés de Lenehan en el dinero, en lugar del amor, su escasez mental, y la usurpación que hace de las víctimas a través de su amigo Corley, nunca lo afectarå10

Al continuar con nuestra secuencia, se presenta otra historia "La casa de huéspedes" y otro personaje, la señora Mooney, muy exigente por cierto. Ella casó con un empleado de su padre, quien le desperdició la fortuna y llegó inclusive al ataque físico. El autor nos dice que "una noche atacó por la espalda a su mujer con un filoso cuchillo, lo que la obligó a dormir en la casa de un vecino". Por lo tanto, "ella se fue a ver al cura y consiguió una separación con custodia de sus hijos"11 ${ }^{1}$. Con lo que quedó del dinero que una vez tuvo, debió empezar un nuevo negocio, una casa de huéspedes.
Aparentemente su fracaso marital no la ha afectado, pero será en este nuevo oficio donde proyectará su frustración emocional en la vida de su hija. Por cualquier medio, ella le procurará a Molly un buen marido.

Paralela a la frustración de la Sra. Mooney, está la del señor Roberto Doran, hombre de 34 años, y víctima de una trampa matrimonial preconcebi$\mathrm{da}^{12}$. Este hombre cae en las manos de una jovencita de 16, Polly Mooney, quien "[tiene] la costumbre de mirar a lo alto cuando [habla], lo que le [da ] un aire de diminuta madona perversa" (D 64) (Subrayado mío). Doran es simplemente un inmaduro, que deberá reparar el honor perdido de la muchacha, y quien a la vez teme encarar las consecuencias de perder el trabajo y el prestigio si se niega a casarse. Así, incapaz de encontrar una solución, se deja atrapar como un escolar y cede ante el matrimonio proyectado por la señora Mooney. El autor nos dice que:

Repitió su frase en un eco, para aplicársela a sí mismo ¿Qué será de mí ahora? Ese instinto del célibe le avisó que se contuviera. Pero el mal estaba hecho: hasta su sentido de honor le decía que ese mal exigfa una reparación $(D, 69)$ (Subrayado mío).

Siendo un hombre tan inocente no se da cuenta de que hay una complicidad silenciosa entre madre e hija, y que todos los inquilinos lo saben. Por eso este "sentido del honor" se entremezcla con amargura al ver cómo otros le planean el futuro.

Llama la atención ver cómo un hombre de 34 años todavía estaba soltero, es, sin embargo,

un cuadro muy realista de ciertas y bien conocidas condiciones sociales de ese período, primero el hecho de que el promedio de edad para casarse en un hombre era entre los treinta y cinco y cuarenta, ya que un hombre en las angustias económicas de Irlanda, no lograba un grado de prosperidad antes de sus treinta y cinco años ${ }^{13}$.

El señor Doran a esa edad, resulta un cebo ideal para Polly y su madre, la Sra. Mooney. Era un hombre devoto, serio y tenía trabajo fijo desde hacía trece años con un vendedor de vinos católico. Por lo tanto, la frustración del señor Doran se debe a su inmadurez, a una falta de estrategia y de un infeliz lance amoroso. "Una vez que el delirio pasa" (D, 69), debe de aceptar a la mujer que no ama y a alguien no apropiado para ser su esposa. Siente que no hay escape para él. No será jamás sino un hombre frustrado emocionalmente.

La señora Kearney, quien es el personaje principal en "Una madre", es otro ejemplo de frustra- 
ción emocional. Es exigente, de carácter fuerte, y espera que no sólo su esposo e hija, sino todo el mundo hagan lo que ella cree que es correcto. Su frustración emocional proviene de no tener lo que ella desea en su matrimonio, es decir una vida brillante. Semejante a la señora Mooney, proyecta su frustración en la vida de su hija y su carrera, al intentar hacer de hacer una pianista excelente. Pero extrañamente, cuando a la hija se le ofrece la primera oportunidad para participar en un concierto público, su madre exige que se le pague inmediatamente. Cuando la gente de la sala de conciertos rehusa hacerlo, la madre se torna irascible e irracional. Desilusionada con la situación, la madre decide que su familia debe partir inmediatamente, echando a perder una oportunidad única. El relato nos cuenta que:

Se quedó inmóvil [ la Sra. Kearney], por un instante, la imagen pétrea de la furia, y, cuando las primeras notas de la canción repercutieron en sus ofdos, cogió la capa de su hija y le dijo a su marido:

ibusca un coche!

... Al cruzar el umbral se detuvo a escudriñar la cara del Sr. Holohan:

-Todavía no he terminado con usted-le dijo $(D, 156)$.

La Sra. Kearney transmite su frustración a los otros mientras trata agresivamente al empresario. Lo único que produce con esta conducta es acentuar su desilución emocional.

El último cuento analizado bajo esta óptica es "Un triste caso", donde encontramos que el señor James Duffy, quien es un solterón de 45 años, está en "el tradicional fin de la edad madura y el principio de la vejez"14. Este es uno de los más interesantes protagonistas de la obra en general, y su vida se halla llena de reveladores detalles. Nos muestra muchos diferentes tipos de frustración. Por el momento, sólo lo contemplaremos dentro de la gama emotiva. El Sr. Duffy es una extraña personalidad, se ha aislado del resto de los mortales, y tiene unas peculiares costumbres y conductas, que son extrañas a la gente de su edad. Por ejemplo, "el Sr. Duffy [aborrece] todo lo que [participe] del desorden mental o físico" (D 112). Además no tiene colegas ni amigos ni religión ni credo. "[Vive] su vida espiritual sin comunión con el prójimo" $(D, 113)$. Como él es incapaz de comunicarse con la gente, es incapaz de amar. Es un ser que su frustra a priori, a tal punto de que ni siquiera come con nadie. Es el tipo esquizofrénico que se rige por un código estricto, que no es otra cosa que una torre de marfil para protegerse de los demás. Por un extraño accidente se involucra en una relación platónica con la señora Emilia Sinico, cuyo esposo es el capitán de un barco, y que se encuentra frecuentemente en alta mar. A pesar de ser un individuo raro, el Sr. Duffy disfruta de la compañía de la dama. Joyce nos dice que "la compañía de ella [es] como un clima cálido para una planta exótica", y que "esta unión la [exalta], [lima] las asperezas de su carácter, [hace] emotiva su vida intelectual" $(\Delta, 115)$. De esto inferimos que él sabe que su vida es bastante aburrida. Pero el Sr. Duffy es un hombre obstinado, y tiene la filosofía de que no puede cambiar: "es imposible la entrega... uno se pertenece a sí mismo" $(D, 115)$. Muy diferente es la actitud de la Sra. Sinico hacia la vida y hacia los hombres; y tan pronto como ella le demuestra la menor señal de afecto, el Dr. Duffy decide terminar su amistad y romance platónico, "todo lazo, dice él, es una atadura dolorosa" ( $B$, 116). Realmente el Sr. Duffy se provee a sí mismo de mecanismos para vivir en un estadio asceta y protegerse de tener algún nexo con el amor o la pasión. Así es que, cuatro años más tarde, cuando lee de la muerte de la señora Sinico, se siente profundamente afectado, la condena por haberse suicidado, luchando por mantenerse firme y de una pieza. Es interesante ver cómo este personaje une su protección física contra la frialdad del ambiente a su protección emocional. Sale de su casa y

se [pone] el sobretodo y el sombrero con premura y [sale]. El aire frfo lo [recibe] en el umbral; se cuela por las mangas del abrigo. Cuando [Ilega] al puente de Chapelizod [entra] y [pide] un ponche caliente $(\mathbb{Q}, 119)$.

El frío penetra su sobretodo, del mismo modo que la noticia de la señora Sinico penetra lentamente en su conciencia y pasión. Es por ello que, una vez que se encuentra dentro de la cantina en el ambiente cálido, se siente indentificado con ella, y medita en la improductividad de su propia vida. Estuvo tan cerca del amor y ahora su caso es tan patético como el de ella.

David E. Jones relaciona al Sr. James Duffy con la vida de James Joyce:

Los lectores por mucho tiempo han visto al Sr. Duffy como el retrato negativo de Joyce, de lo que habría sido si se hubiera quedado en Dublín. Hay en realidad razón para creer que Joyce habfa concebido a Dublineses como una encarnación de sí mismo. Para junio de 1910, él [Joyce] escribió a G. Molyneux Palmer diciéndole, 'No creo que me reconocerás de primera entrada en él [J. Duffy], que es algo amargo y sórdido 15 . 
No se puede separar a la Sra. Sinico y su frustración de la figura del Sr. Duffy, ya que la de ella se evidencia desde el principio, al no recibir amor de nadie. Los hombres con los que entra en contacto, tales como el Capitán Sinico y el Dr. Duffy no se lo proporcionan. Emilia Sinico era una mujer de cuarenta y tres años, "su esposo era capitán de un buque mercante que hacía la travesía en tre Dublín y Holanda, y no tenían más que una hija" ( $(\theta$, 114). El autor describe a la señora Sinico diciendo que "su cara que debió ser hermosa, era aún inteligente: un rostro ovalado de facciones decisivas. Los ojos eran de azul oscuro y firmes $(Q, 113)$. Cuando asistía a un concierto en la Rotunda con su hija, la Sra. Sinico conoció al Sr. Duffy. Una observación casual sobre el poco auditorio presente esa noche, fue la excusa de ella para hablarle. Se volvieron a encontrar en Earlsfort Terrace, y el Sr. Duffy "[aprovechó] el momento en que la hija estaba distraía para intimar" $(D, 113)$. A través de las palabras de la dama, nos damos cuenta de que no era feliz en su matrimonio y que había una evidente frustración emotiva, "ella aludió una o dos veces a su esposo, pero su tono no era como para convertir lo mencionado en un aviso de alerta" (Subrayado mío) ${ }^{16}$. A partir de este momento el Sr. Duffy la visitó en su casa, y "el capitán Sinico propiciaba tales visitas, pensando que estaba en juego la mano de su hija" $(D, 1114)$. Consecuentemente, el "Sr. Duffy tuvo muchísimas ocasiones de disfrutar la compañía de la dama" $(D$, 114). Es comprensible y de esperar que una mujer de su edad, que frecuentemente permanecía solitaria por la ausencia de su esposo, se enamorara de un hombre como el Dr. Duffy. Aparte de su extraño comportamiento, el Sr. Duffy parecía ser interesante en la conversación y "poco a poco sus pensamientos se ligaron a los de ella" $(D, 114)$. En un principio la Sra. Sinico no sintió por el Sr. Duffy más que una amistad. Hubo inclusive momentos en que ella se convirtió en una especie de madre para él, un sentimiento muy apropiado para un solterón de su tipo; "con solicitud casi mąternal ella lo urgió a que le abriera su naturaleza de par en par; se volvió su confesora" $(D, 114)$. La identificación de la dama continuó hasta el punto en que le hizo patentes su sentimientos: "La señora Sinico le cogió una mano apasionadamente y la apretó contra su mejilla" $(D, 115)$. Este momento se torna crucial para la señora, pues a partir de aquí es rechazada por el caballero, dando ésto inicio a todo un vía crusis. La señora quien posee una personalidad muy débil, se siente incapaz de mantener su com- postura. Es así como el señor Duffy y la señora Sinico van a vivir un drama paralela y separadamente; el primero sigue con vida, impecable como siempre, pero tan muerto como la señora, que de este modo encuentra un medio de escape a su existencia.

La frustración emocional está presente en muchos de los protagonistas de Dublineses. Ellos son el producto de diversos aspectos y momentos que provocan este tipo de extrañas reacciones. Asimismo, el sexo no puede ser excluido de lo emocional, ya que tiene muchos y complicados matices, por ser un aspecto intrínseco de la naturaleza del hombre. Es en verdad tan complicado como el Laberinto del Minotauro, y es otro de los caminos de la frustración.

En "Polvo y ceniza", María, la protagonista, tiene 45 años y está sexualmente frustrada. Joyce la describe como una persona muy pequeña con "una nariz y una barbilla muy largas" (D, 103). Y nos dice que "la punta de la nariz casi le [ toca] la barbilla" $(D, 105)$. María nunca ha sido amada como mujer, y nos da la impresión de un ser asexuado. No teniendo hijos propios, cria a dos muchachos, los Donnellys. Es casi una monja laica y sin votos. Se preocupa y cuida a todos los semejantes que puede, en especial a las mujeres que trabajan en la lavandería Dublín Iluminado (Subrayado mío). Para algunos críticos ella integra elementos de santa y bruja ${ }^{17}$. Por ejemplo, las plantas que ella cultiva --helechos y begonias-- son tradicionalmente símbolos cristianos de humildad, santidad y vida eterna los primeros, y de brujería y muerte las segundas ${ }^{18}$. Pero exceptuando este tipo de evidencias, no tenemos ningún hecho feaciente que nos indique que María se ha ofrecido al Señor por amor a los otros, cosa que nos la convierte en un ser humano común y corriente.

La frustración de María es algo que no podemos ver, pero sí podemos inferir de su suave y particular conducta. Por ejemplo, camino a la casa de los Donnellys, ella conversa con un caballero que le cede el asiento en el tranvía. La mujer se siente adulada, y hay evidencia de que le agradó el caballero como hombre, ya que nos dice que su pensamiento que "[parece] un coronel" y además nota que "[es] mucho más gentil que los jóvenes que sólo miran de frente" $(D, 106)$. El hombre comienza a conversarle y "María [ está] de acuerdo con él y lo [demuestra] con su asentimiento respetuoso y sus ejemes" $(D, 106)$. Al considerarlo de aspecto militar, lo asocia con la idea victoriana de que los varones castrenses eran considerados guapos y va- 
lientes. En el Dublín Iluminado, en donde ella vive, Lizzie Fleming (una lavandera), le "[dice] que está segura que a María la [va] a tocar el premio con anillo y todo"19, cuando todas participan de este tradicional juego de acertijos a la hora de la comida, como parte de la celebración de la fiesta religiosa de Todos los Santos. Esto, por supuesto son indicios de boda y placeres sexuales. A todo esto María le responde que "no [desea] ni anillo ni novio" (D, 105). María lo dice riendo, pero "sus ojos verdegris [ brillan] con timidez y desilusión (Subrayado mío $)^{20}$, lo que indica que dentro de su yo interno, sí le habría gustado que esto fuera realidad. María pierde el juego de la Lavandería, entonces vuelve el rostro hacia la religión, a la misa de mañana, como un consuelo. Hay además otros elementos que nos indican su frustración sexual. Camino a casa de los Donnellys, les quiere comprar un regalo, y decide que nada mejor que una tarta. Albert Salomon nos afirma que en "los juegos de la víspera del Día de Todos los Santos, se describen varios entretenimientos típicos de esa fiesta de Halloween, dos de los cuales son de interés peculiar para los lectores de "Polvo de ceniza". El primero se relaciona con los pasteles,

El detalle más importante de la Víspera es sin duda la tarta encantada. Esta debe ser decorada como un pastel de bodas, y ser lo suficientemente grande para que cada invitado reciba su buena porción, para que todos así puedan compartir la búsqueda de los símbolos secreta y profundamente escondidos en él: un anillo de matrimonio, monedas como augurio de bienestar y una medalla de oro como signo de bendición ${ }^{21}$.

La tarta de bodas se menciona dos veces en la historia, una vez en la Lavandería y otra en la tienda de Henry Street, esta vez como un pastel de ciruelas.

El profesor Hubert McDermott, del University College en Galway, Irlanda, piensa que el nombre en inglés de "Polvo y ceniza", CLAY, le puede traer la colación al lector irlandés la palabra clé, que es gaélico se pronuncia exactamente igual que clay. El significado de clé es simplemente izquierdo (mala suerte), como mano izquierda. La clave que nos indica esta relación entre estas dos palabras se halla en la escena climática de la historia, la cual tiene lugar en la casa de los Donnellys, cuando María toma parte en el juego. El juego en sí es simple, ya que se ponen varios acertijos dentro de unos platillos: a cada jugador se le vendan los ojos, y luego se le pide que escoja uno al tocar- lo. Cada vez que un jugador participa, los acertijos se les cambia de lugar. Lo que contiene cada plato tiene un significado: el agua es un viaje por mar; el anillo es matrimonio; el dinero, es una herencia. A todos estos inocentes acertijos, los niños de la casa añaden clay o arcilla. $Y$ es precisamente lo que María escoge $e^{22}$. Es por ello que la "señora Donnely le [dice] algo muy pesado a una de las vecinas: que [bote] todo eso enseguida: así no se [juega]" $(D, 109)$. Para los profesores McDermott y Walzl, María ni se casará ni se hará monja, sin embargo "ella dormirá solamente en brazos de la muerte",23.

Cuando María está en la fiesta, canta una canción Soñé que habitaba, sin querer omite parte del texto, que se refiere a las propuestas de matrimonio. No nos queda más remedio que creer que no tendrá más alternativa. María es una perdedora en todos los juegos, en especial el del amor y el del sexo, "nunca ha participado en la batalla del sexo, pero admite que a pesar de todo tiene un cuerpecito bien hecho"' (Subrayado mío) ${ }^{24}$. María finalmente busca refugio en la religión, es su destino. Florence L. Walzl dice que María representa el destino histórico de la mujer irlandesa, de la cual, gran cantidad no casará nunca y otras tienen que abandonar el país ${ }^{25}$, sin embargo creemos que también representa la frustración de la mujer que se queda sola y sin casarse.

Anteriormente analizamos al Sr. James Duffy, y ahora lo retomamos. Su frustración evidentemente eclipsa su desencanto sexual. Parece ser incapaz de tener cualquier relación sexual. El mismo autor lo sugiere cuando expresa que "era un desterrado del festín de la vida" $(D, 121)$. No es extraño que el Sr. Duffy pensara que "un ser humano parecía haberlo amado y él le negó la felicidad y la vida" $(D$, 120). Ya sabemos que el Sr. Duffy no cree ni en la amistad ni en el amor, pero sí hace alusión al sexo. El quid de todo este asunto del sexo y la amistad reside en la frase que él escribió dos meses antes de la muerte de la señora Sinico "el amor entre hombre y hombre es imposible porque no debe haber comercio sexual y la amistad entre un hombre y una mujer es imposible porque debe haber comercio sexual" $(\mathbb{Q}, 116)$ (Subrayado mío). Esta línea de pensamiento va contra todas las reglas de la lógica en lo que se refiere a la amistad y al amor; ya que puede haber amor entre dos hombres sin sexo alguno, $y$ amistad entre un hombre $y$ una mujer sin sexo alguno, tampoco. Las palabras del Sr. Duffy son contrarias a las de Joyce al Sr. G. 
Molyneux Palmer en relación con la creencia generalizada de que el Sr. Duffy es la encarnación de la personalidad del autor, puesto que Joyce fue siempre un individuo fiel como amigo tanto a hombres como mujeres, además de que como hombre fue muy sexual.

El señor James Duffy no se logra liberar de su frustración ni emocional ni sexual. Permanecerá desilusionado con su vida de asceta improductivo, incapaz de expresar amor ni tener relaciones sexuales.

Una vez más retomamos a Corley y Lenehan, ambos protagonistas de "Dos galanes". Corley es un buen ejemplo de desilución en el ámbito sexual, aún cuando parece tener éxito en estos menesteres. Como habíamos mencionado anteriormente, estos dos señores viven bajo un código bastante lejano de la circunspecta moralidad victoriana. Cuando Corley le habla a Lenehan, le alardea de su éxito con las mujeres. Le cuenta cómo a una "le [pasa] el brazo por arriba y la [aprieta] un poco esa noche. Entonces el domingo siguiente, tiene cita con ella y la [ve]"26. Además impresiona a Lenehan y le cuenta cuán interesante es él para las mujeres, y que ellas creen que él "[es] de buena familia" $(D$, 53). Aún cuando este galán tiene un alto concepto de sí mismo, confiesa sus fracasos en el área sexual con muchachas de mejor condición social. Solía salir con señoritas a las que sacaba de su casa (del South Circular, o barriadas al sur de Dulbín), pero ahora se lamenta de las atenciones y dinero que gastó en ellas; a pesar de que le gustaba sacarlas en tranvía y pagarles todas las invitaciones al teatro, dulces, chocolates; amargamente dice "maldita sea lo que saqué de todo eso"2 7 . El haber empujado a una mujer a la prostitución sí parece pesar en su conciencia, "ella estaba... bastante bien-dice con sentimiento" $(D, 55)$ (Subrayado mío). Le cuenta a Lenehan que él la vio con dos hombres dentro de un auto, calle abajo de Earl Street. Se autojustifica diciendo "hubo otros antes que yo" $(D, 55)$. Lenehan, quien sabe la verdad del asunto, le replica "-Tú sabes que tú no me puedes andar a mí con cuentos" ( $D, 55)$, a lo que Corley dice "itriste traidora! " $(Q, 55)$. Después de esta escena, Corley se convierte en un gigolo barato. Es un frustrado y es al mismo tiempo insensible como para percatarse de su fracaso a nivel del sexo. Es un protagonista que pierde todo sentido de dignidad, $y$ al final de la historia, con pasmosa indiferencia "[extiende] una mano hacia la luz $y$, sonriendo, la [abre] para que la [contemple] su discípulo. Una monedita de oro [brilla] sobre la plama" $(D, 62)$
(Subrayado mío). La sirvientilla de clase baja le había pagado, una vez que había terminado el paseo de aquella tarde.

Como lo indica el profesor Epstein, Corley, cuyo físico es similar a un falo erecto, vive frustrado a costa del dinero de la sirvientilla ${ }^{28}$. Corley vive o vegeta en un eterno statu quo, si hacer el menor esfuerzo por remediarlo, y de alguna manera transmite al lector su insatisfacción.

La historia final, titulada "Los muertos", la más larga del libro se lleva a cabo en una fiesta concierto en la casa de unas señoritas Morkan. La acción se centra sobre los protagonistas Gabriel y Gretta Conroy, que son marido y mujer. Gabriel sufre una desilusión sentimental y sexual. Una precede a la otra al final del cuento. Poco antes de esto, ambos salen de la fiesta, cuando un tenor está cantando una canción que se titula La joven de Aughrim, y se van a pasar la noche al Hotel Gresham, donde Gabriel piensa revivir su luna de miel. En ese momento, el hotel no tiene electricidad, y cuando al marido le ofrecen unas candelas, dice que mejor no, que la luz de gas de la calle es suficiente. Quiere que el ambiente sea perfecto para hacerle el amor a su esposa. Ya antes, camino al hotel, Gabriel sentía que iba "galopando a alcanzar el barco, galopando hacia su luna de miel" $(D, 223)$. Sin embargo cuando están solos en la recámara, el hombre percibe de un modo extraño que el ambiente no está listo para los deleites carnales: "Su cara [de ella] lucía tan seria y fatigada que las palabras no acertaban a salir de los labios de Gabriel. No, no era el momento todavía $(Q, 225)$. Para disipar un poco la tensión, ambos hablan, y mientras esto sucede, Gabriel piensa que "tomarla así como [está] sería bestial. No, [tengo] que notar un poco de pasión en sus ojos. [Desearía] dominar su extraño estado de ánimo" $(B, 225)$. Debido a lo intenso de su pasión Gabriel no se percata de que ella se le acerca desde la ventana, se alza en la punta de sus pies y lo besa. Esta súbita reacción lo sorprende $y$,

temblando de deleite ante su beso súbito... le [pone] una mano sobre el pelo y [empieza] a alisárselo hacia atrás, tocándolo apenas con los dedos. El lavado se lo había puesto fino y brillante. Su corazón [desborda] de felicidad. Justo cuando lo deseaba había venido ella por su propia voluntad. Quizás sus pensamientos corrfan acordes con los suyos. Quizás ella sintiera el impetuoso deseo que él guardaba dentro y su estado de ánimo imperioso la había subyugado $(D, 226)$.

Todo parece indicar que el momento es perfecto para una noche de amor, pero Gabriel todavía per- 
cibe que algo no está del todo bien, y le pregunta qué sucede. De primer momento ella no le contesta, pero explota en llanto y contesta "-oh, pienso en esa canción, La joven de Aughrim" $(Q, 226)$. EI texto de la canción le recuerda a Michael Furry, un mozuelo que se había enamorado de ella, cuando vivía en su pueblo natal, Galway. El solía cantar esa canción, y ahora Gretta recuerda que en una lluviosa noche, después de haber estado enfermo en cama por muchos días, la vino a despedir y murió de pulmonía a consecuencia de esa salida nocturna. Este momento tan inesperado, torna la noche de Gabriel en una total frustración, al darse cuenta de que Michel Furry ha dejado hondas huellas en su esposa, y que no puede luchar contra alguien que está muerto. Después de estos instantes de sentimiento y frustración sexual, Gabriel va a vivir en epifan $i^{29}$. Gabriel yace en la cama junto a su esposa y piensa que ella ha conservado la memoria de su amado por tantos años, y esto lo hace llorar y darse cuenta de que "nunca había sentido aquello por ninguna mujer, pero [sabe] que ese sentimiento [tiene] que ser amor" (D 231). Este es el inicio de su visión o epifanía en tanto que

a sus ojos las lágrimas [crecen] en la oscuridad parcial del cuarto y se [imagina] que [ve] una figura de hombre joven, de pie bajo un árbol anegado. [Hay] otras formas próximas. Su alma se [acerca] a esa región donde moran las huestes de los muertos. [Está] consciente, pero no [puede] aprehender sus aviesas y tenues presencias. Su propia identidad se [esfuma] a un mundo impalpable y gris: el sólido mundo en que estos muertos se criaron y vivieron se [disuelve] consumiéndose $(Q, 231)$.

Inmediatamente después de todo esto unos "leves toques en el vidrio lo [hacen] volverse hacia la ventana" $(D, 231)$, poniendo fin a esa visión que es el episodio que marca el climax del cuento. La epifanía de Gabriel lo hace reparar en cuánto ama a su esposa, y sus lágrimas exaltan ese sentimiento. Comprende su inseguridad como marido y se da cuenta de que no ha vivido nada realmente. La frustración sexual de Gabriel es reforzada por un detalle simbólico bien adecuado al momento "una bota se [mantiene] en pie, su caña flácida caída; su compañera [yace] recostada a su lado" $(D, 230)^{30}$.

Aún cuando Gabriel sufre de una intensa pero pasajera desilución sexual y emocional, el fracaso de esa noche no va a afectar su vida conyugal. Su esposa solamente tuvo un mal momento procovado por la festividad de esa noche, nada indica que ella no lo ame. Al particular, la doctora Francesca
Romana Paci, resume el fin de "Los muertos", citando a su vez al profesor Praz en Due maestri dei moderni, de la siguiente forma:

...La fiestecilla de la primera parte, el discurso de Gabriel y la dramática y elegfaca conclusión forman un conjunto habilísimamente orquestado... recogiendo como en un símbolo el sentido de la fragilidad humana y cerrando el todo con un fin de sinfon $\mathrm{Ca}^{31}$.

De todas las historias que figuran en Dublineses, ninguna contiene líneas tan llenas de tal ardor y pasión como la narración a que nos referimos. De algún modo le recuerdan al lector las cartas de James Joyce, a su esposa, Nora Barnacle, de 1903 a 1912.

"Un encuentro", es la historia de un sensible niño y de su enfrentamiento con un mundo sórdido. Estanislao Joyce nos da un recuento de tal hecho:

En Encuentro, mi hermano describe un día en que resolvimos escaparnos de casa, cuando vivíamos en la calle North Richmond y nos encontramos con un viejo pederasta. A nosotros nos pareció un papanatas. Ninguno de los dos tenía entonces noción de qué clase de 'papanatas' era, pero algo divertido en su manera de hablar y en su conducta nos puso en guardia en seguida. Pensamos que era un loco que se había fugado (Subrayado mío) ${ }^{32}$.

Tres muchachos deciden escaparse un día de la escuela y visitar el Pigeon House, que era la planta de electricidad de Dublín. Para llevar a cabo esto, planean una estrategia, en la cual incluían excusas con notas falsificadas, hechas por la hermana de uno de los muchachos para los jesuitas del colegio, así como el tiempo exacto en que debía volver a casa--antes de las cuatro de la tarde-- para no ser descubiertos por sus respectivos padres. Uno de los muchachos, al final decide no ir, y la aventura la van a vivir únicamente Mahony y el protagonista. Como el tiempo se les acorta, no pueden llegar al Pigeon House, por lo que van a quedarse en un potrero vacío, en donde encuentran al viejo papanatas (Subrayado mío).

La aparición de este individuo es relativamente muy corta, pero suficientemente abundante en detalles reveladores de los muchos perturbados aspectos de su personalidad, tal como exponer a los muchachos al sexo pervertido. En la historia, el desconocido aborda a los muchachos, primero hablándoles de cosas inocuas, tales como el tiempo, o cuán felices son los días escolares, no sólo para él sino para cualquiera, y asimismo que daría cualquier cosa por ser joven de nuevo. Poco a poco 
entra en temas más serios, como hacer un comentario sobre la poesía de Tomás Moro, Sir Walter Scott y Lord Lytton, con el ánimo de impresionar a los muchachos con su conocimiento de tales temas. Después de esto, va al grano, a las sugerencias sexuales: "Todos los muchachos- [dice]- tienen noviecitas" $(D, 26)$, y les pregunta a ambos que cuántas tienen. Esta actitud al principio impresiona al protagonista, quien encuentra que el individuo es bastante liberal para su edad, y cuán razonables suenan sus palabras. No obstante, todo esto, el protagonista observa cuidadosamente al hombre, pero Mahony por otro lado, no parece estar pensando lo mismo. Entre tanto, el hombre llega a un punto tal que no puede controlarse a sí mismo y habla de las jovencitas sin parar, de cuán suaves son sus manos, "[repite] sus frases una y otra vez, variándolas y dándoles vuelta con su voz monótona" $(D, 26)$. Se perturba tanto que le "[dan] tembleques una o dos veces, como si temiera algo o como si de pronto tuviera escalofrío" $(Q, 26)$. Inesperadamente se pone en pie y se aleja hacia el final del terreno. Lo que realiza inmediatamente después de esto hace que Mahony exclame: "iMira eso! iMira lo que está haciendo ahora!" $(D, 27)$. El protagonista ni siquiera levanta la mirada. Tiene miedo, tal vez, pero permanece inmóvil en su sitio. Inmediatamente después de esta escena, el hombre retorna a su sitio anterior como si nada hubiera sucedido. Su actitud hacia los muchachos y las muchachas ha cambiado radicalmente, y se contradice a sí mismo diciéndoles a ellos que deberían azotarlos por tener noviecitas "cuando un muchacho [sale] travieso y malo" dice "no [hay] nada que le [haga] tanto bien como una buena paliza" $(D, 27)$. El cuento finaliza cuando Mahony persigue a un gato por todo el terreno, y el protagonista, a quien muchos han identificado con Joyce y que permanece junto al viejo decide finalmente marcharse "[sube] la cuesta en calma pero [su] corazón [late] rápido del miedo de que [lo] [agarre] por un tobi"lo" (D 28). En verdad eso es todo lo que sucede el "viejo papanatas" evidentemente tiene una conducta sexual anormal, tal como sadismo, homosexualidad, o simplemente exposición indecente; el texto es bastante ambigüo y se presta para muchas interpretaciones. Pero lo que sí está claro es que el hombre no pide absolutamente nada a los muchachos, aunque sí los asusta mucho. Florence L. Walzl dice que "Un encuentro" es un cuento que tiene que ver explícitamente como la homosexua$\operatorname{lidad}^{33}$, pero Zack Bowen no está del todo seguro cuando dice: ya fuera que el hombre se estế masturbando u orinando, no está del todo claro, pero sí se está manipulando de alguna manera y este acto está ligado con sus pensamientos sobre el sexo y las mujeres inicialmente, y luego con sus impulsos sádicos de azotar a los muchachos por tener noviecitas ${ }^{34}$.

A pesar de todo lo que los críticos dicen, parece que hay una fuerte frustración homosexual en el "viejo papanatas". Esto lo enfatiza el diálogo entre el protagonista y el hombre, la segunda vez que se sienta junto a él, por la extraña mirada de sus ojos "verde botella" bajo una frente fruncida, y por el tono de su voz que se hace casi afectuosa como si le rogara que lo entienda o pidiéndole complicidad.

“' 'Las hermanas' es una muy desconcertante historia que ha inquietado a los críticos joycianos por más de dos décadas al tratar de descubrir su misterio"35. Este fue el cuento que más revisó Joyce, y en el que más trabajó, como así lo indican los numerosos borradores y pruebas. Estas revisiones nos ofrecen varias claves interesantes, especialmente desde el punto de vista textual, eje de nuestro interés principal. Como es evidente, los críticos lo han enfocado desde muchos puntos de vista. Por ejemplo Eileen Kennedy afirma que los estudios pueden dividirse en naturalistas y simbólicos, cuando se refiere a la síntesis comprensiva de Florence L. Walz| $\left.\right|^{36}$.

"Las hermanas" fue inicialmente publicado en un periódico irlandés The Irish Homestead, a principios del verano de 1905, en una sección llamada "Nuestra historia semanal". Las versiones modernas varían mucho de la original, sin embargo los personajes principales en todas las versiones son el sacerdote, las hermanas y el niño, cuya consideración varía bastante en los últimos manuscritos, tanto así que en la versión original "no hay sugerencias en cuanto a conducta inmoral o trazos de sodomía" (Subrayado mío) ${ }^{37}$. A pesar de que existen otras diferencias en los protagonistas, lo que nos interesa ahora es la frustración de uno de los personajes más importantes, el padre James Flynn, tal y como aparece en la versión moderna.

El personaje principal de "Las hermanas" es un niño a quien los críticos han identificado con James Joyce. Este jovencito hace amistad con el padre James Flynn, quien es un sacerdote viejo y paralítico, que a su vez enseña al muchacho cosas acerca de la Iglesia, la doctrina, ritos, y hasta anécdotas de su vida pasada. El lector se familiariza con la historia a través del niño y de lo que otros personajes dicen. El padre Flynn es un individuo que 
puede estudiarse desde muchos puntos de vista, no obstante ahora nos interesa como frustrado sexual. Tal y como la doctora Walzl lo sugiere, en Dublineses "todo depende de inferencias" 38 , es así que nosotros debemos inferir que el padre vive una frustrada y marcada apetencia homosexual, tal vez pederastria. Para empezar, por ejemplo, las palabras del viejo Cotter al tío del muchacho, nos dan la primera pista:

-No, yo no diría que era exactamente... pero había en él algo raro... misterioso. - Yo tengo mi teoría - dijo-. Creo que era uno de esos.. casos... raros... Pero es difícil decir... - No me gustaría nada que un hijo mío-dijo-tuviera mucho que ver con un hombre así.

-Es malo para estas criaturas - dijo el viejo Cotter- porque sus mentes son muy impresionables. Cuando ven estas cosas, sabe usted, les hace un efecto... $(\mathbb{Q}, 9,10,11)$ (Subrayado mío).

Nos podemos dar cuenta de que se refieren al padre como raro, y el texto inglés usa una palabra: queer, cuya connotación se refiere la mayoría de las veces a homosexual ${ }^{39}$. Otros significantes los podemos obtener de las palabras del niño, especialmente cuando nos relata un sueño que tuvo en el cual ve la cara gris del paralítico persiguiéndolo y "[siente] que su alma [recula] hacia regiones gratas y perversas" $(\otimes, 11)$. Hay otras sutiles y extrañas sugerencias de algo misterioso y pecaminoso y la referencia a Persia como tierra "de costumbres extrañas" $(D, 14)$. Esta fantasía intriga al muchachito y la idea de "una lámpara colgante de las antiguas" ( $D, 14)$ (Subrayado mío) definitivamente tiene matices fálicos. El jovencito también hace referencia a las preguntas del sacerdote sobre lo que uno debería hacer en ciertas circunstancias, tal es el caso de si todos los pecados son mortales o solamente imperfecciones. En sus observaciones el çura no es claro en cuanto a qué tipo de situaciones particulares se refiere, y luego la gravedad de los pecados es otra clase para su frustración. Una cosa sí debe de quedar bien clara: al muchacho nunca le pasó niada, tal-como abordamiento de índole sexual por parte del sacerdote. Es factible que el muchacho haya inferido algo extraño por parte del sacerdote, debido a sus preguntas particulares, o a la historia de su vida. Esto lo vemos en el contenido del sueño del jovencito, anteriormente mencionado, aún cuando para él sea solamente una vaga percepción subconsciente, y que no le esté clara del todo. Ser hemofílico es un peso muy grande en un hombre de Dios, además de que el sexo le está vedado por sus votos. Ahora en relación con el padre Flynn, pensamos que su homosexualidad no lo hizo paralítico, pero sí debió de darle gran tensión y sufrimiento mucho antes de que se enfermara; es importante hacer resaltar que esta situación del saçerdote se agrava al darse en un contexto victoriano. Al respecto, la Dra. Walzl, refuerza nuestro pensamiento cuando indica que "dado el estado de invalidez del sacerdote, homosexualidad manifiesta es extremadamente improbable" ${ }^{\prime 40-}$

Hemos deducido la condición homosexual del presbítero, así como su subsecuente frustración, del lenguaje en el cuento y de algo que Joyce mismo le dice a su hermano Estanislao, en una carta que le escribió después de que habló con su editor irlandés. La carta está fechada el. 20 de agosto de 1912, y dice:

Ví a Roberts otra vez. Me preguntó minuciosamente si había sodomía también en 'Las hermanas' y que qué era simonía...

Te adjunto una carta de Lindwell. Sabré que hacer ahora (Cartas, II, 305-6) (Subrayado mío).

Esta carta que menciona de último es del señor John C. Lindwell, y se relaciona con un Comité de Vigilancia, "cuyo objetivo era vigilar y suprimir todos los escritos con contenidos inmorales..." (Cartas, II, 306). Lo único que podemos decir, para concluir, es que, la frustración sexual del reverendo James Flynn acompaña su alma, lo mismo que la parálisis de su cuerpo.

Contemplaremos ahora el tercer paso de nuestro análisis: la frustración y aniquilamiento del yo de los personajes. Debemos señalar que la autoestima es un sentimiento que juega un papel muy importante en la personalidad saludable de cada individuo. Todos tenemos, hasta cierto grado una actitud positiva hacia nuestra personalidad y toda su estructura, no importa cuán jóvenes o viejos seamos. Ahora bien, cuando algo o alguien nos molesta y nuestro amor propio es maltratado, respondemos casi de inmediato con conflictos y ansiedad, que evidentemente nos crean una frustración. En Dublineses, el yo de los personajes se ve afectado por la acción de los demás, es decir por el contexto social. Hacemos nuestras, de nuevo, las palabras de Raúl H. Castagnino cuando dice que alşunos personajes son:

...identificables con el creador, nacidos de la introspección y auto-observación de éste... también los hay nacidos de la observación exterior, de la penetración psicológica del creador, que sabe mirar a su alrededor y describirá quien vive con él 41 . 
por lo tanto vamos a tener que recurrir al simbolismo de vez en cuando para explicar el significado de algunos personajes.

Inicialmente hay tres casos de aniquilamiento en los protagonistas de las tres primeras historias de Dublineses. Para algunos críticos, ellos son la proyección de un joven James Joyce, para otros son tres jóvenes diferentes. Personalmente, nos inclinamos a creer que es la misma persona en diferentes estadios de crecimiento, de la niñez a la adolescencia. Es importante resaltar que, aunque no son graves casos de frustración, son hechos que influyen grandemente la idea del propio yo que tienen los jóvenes.

Al inicio de "Las hermanas", el protagonista se encuentra en una situación familiar, está sentado a la mesa; su tío, tía y un visitante, el viejo Cotter, hablan sobre la muerte recientemente del padre Flynn. Para evitar que el jovencito entienda, los mayores, en especial el viejo Cotter, usan frases incompletas, y hacen alusiones al sacerdote que del todo no quedan muy claras para el muchachito. Los adultos piensan que es todavía muy joven para explicarle con exactitud qué era lo que andaba mal con el viejo paralítico. Este particular momento, es para el niño el punto de partida de la frustración de su autoestima, cuando se da cuenta de que es el centro de atención. Siente que le tratan como si fuera muy niño, muy idiota o inocente para que le hablen francamente, sin reservas. Para contrarrestar el momento, pretende no poner atención y concentrarse en lo que está comiendo. Si levanta los ojos del plato, siente al viejo y "sus ojos de azabache [observándolo]" $(\boldsymbol{D}, 10)$. Debe de controlarse "por miedo a dejar escapar [su] furia" $(D$, 11.), y piensa que el viejo Cotter es un "viejo cansón, nariz de pimentón" $(D, 11)$. No puede evitar sentirse incómodo. Es normal que un niño así se sienta frustrado en un mundo de adultos, al que no pertenece y que además, lo ignora.

En "Un encuentro", el protagonista también da signos de un yo lastimado. Este joven tiene un alto concepto de sí mismo. Esto se refleja en las palabras del padre Butler -que el protagonista hace suyas, más adelante en la historia- cuando se da cuenta de que sus estudiantes han estado leyendo El jefe apache, sobre lo que el maestro comenta: "Me sorprende que jóvenes como ustedes, educados, lean cosa semejante. Lo entendería si fueran ustedes alumnos de... escuela pública" $(D, 20)$ (Subrayado mío).

En el cuento, los muchachos se encuentran a sí mismos en condiciones de escaparse de la escuela e ir solos tan lejos como el Pigeon House, para sentir "el hambre de sensaciones sin freno, del escape que solamente [las] crónicas desaforadas parecían ser capaces de [ofrecerles] " $(D, 20)$. Los primeros signos de frustración del amor propio por parte del protagonista, aparecen cuando se encuentra al viejo papanatas y le miente diciéndole que ha leído los libros que éste menciona. Cuando Mahony cuestiona al viejo sobre los libros que no debe de leer, el protagonista se molesta y agita; teme que el "hombre [fuera] a creer que [el] [era] tan tonto como Mahony" $(D, 25)$ y esto lo frustra inicialmente. También cuando el viejo hace referencia a los azotes, el muchacho se siente tentado a replicarle indignado que ellos "no [son] alumnos de escuela pública para que [les] dieran una buena, como [dice] -el" $(D, 27)$. Igualmente, cuando en la conversación el viejo papanatas les pregunta si tienen noviecitas, el muchacho responde mintiendo, ya que no quiere que el desconocido se percate que no tiene ninguna. $Y a$ al final de la historia $y$ cuando el joven decide dejar la compañía del viejo, llama a Mahony por el nombre de Murphy (con anterioridad se habían puesto de acuerdo en usar seudónimos en presencia de extraños). Esta escena refuerza su frustración ya que usa un tono de voz diferente para dar la impresión de que no está asustado (Subrayado mío). Se percata de que está actuando y se avergüenza de "treta tan burda" ( $D$, 28). Sin embargo, ha de llamar a Murphy dos veces antes de que lo oiga y dejarse venir corriendo como si viniera de algún modo a ayudar al personaje narrador. Todo esto sólo contribuye al crescendo de su frustración, y al mirar a Mahony piensa que se "[siente] un penitente arrepentido: porque dentro de [él] [ha] sentido por Mahony siempre un poco de desprecio" (D, 28). Con esas palabras, Joyce emula la Biblia, específicamente Samuel II, 6; donde Mical, hija de Saúl, ve a David Danzando ante el Señor, y entonces la mujer "al ver al Rey David haciendo piruetas y cabrilas delante del Señor, lo despreció en su interior" (Samuel II, 6, 16) (Subrayado mío). El castigo para la mujer es que "Mical, hija de Saúl, no tuvo hijos en toda su vida" (Samuel II, 6, 23).

La frustración de este muchachito no es otra cosa que un rato desagradable y un susto en la vida de un pre-adolescente.

Así el protagonista de "Arabia" es también otro ejemplo de este tipo de frustración. El es mucho mayor que los protagonistas de "Las hermanas" $y$ de "Un encuentro", además es ya un adolescente interesado en las muchachitas y suficientemente 
grande para permitírsele salir de la casa a las 9 p.m., e ir solo a la feria. "Arabia" es la historia de un amor entre un jovencito por una mujer más madura que él. Es precisamente esta muchacha la que le pide que vaya a la feria, a la que se ha hecho propaganda como [sic] Grand Oriental Fête y era a beneficio del Hospital de la calle Jervis, regentado por las monjas de la caridad ${ }^{4}$.De esta manera el muchacho sueña por varios días con ir a este sitio, y hasta su trabajo escolar se ve afectado por la expectativa. Finalmente llega el día: su tío, quien debe darle no sólo el permiso sino el dinero, llega tarde a la casa, a pesar de que en la mañana el sobrino se lo había mencionado. Cuando finalmente arriba a casa, exaspera al muchacho con comentarios sarcásticos tales como "ya todo el mundo está en la cama y en su segundo sueño" $(D, 34)$. Luego se excusa por molestarlo, pero una vez que el joven le dice que va a la feria, el tíole pregunta si sabe un poema que se llama "Un árabe dice adiós a su corcel"' $(D, 4)$ y continúa irritando al chico. Todo parece estar en contra de su visita a la feria, incluso el tren que permanece más tiempo que se costumbre en la estación y que luego sale lentamente. El protagonista está lastimado en su fuero interno por todo lo sucedido, además a su llegada a la feria está el hecho de descubrir que ya ha cerrado, tiene las luces apagadas y no era exactamente el lugar que había imaginado. Todo lo anterior hace al protagonista experimentar una mezcla de sentimientos encontrados: furia, autocompasión y burla, tal como se describe en su epifanía: "levantando la vista hacia lo oscuro, me ví como una criatura manipulada y puesta en ridículo, por la vanidad; y mis ojos ardieron de angustia y de rabia" $(0,35)$ (Subrayado mío).

Podemos resumir el caso anterior diciendo que lo vivido es una situación que se escapa de las manos del muchacho, y no es otra cosa que los índices de que un adolescente se está acercando a la madurez, y a pesar de todo, en su corazón, sabe que todavía es un muchacho. Esta y las frustraciones antes mencionadas no son nada serio, solamente un asunto de amor propio contrariado.

Para continuar con nuestro análisis, tenemos al señor Roberto Doran en "La casa de huéspedes", quien también sufre una desilución del yo interno. Como lo indicamos anteriormente, ha sido forzado a casar con Polly Mooney, después de caer en una trampa de matrimonio. Como consecuencia de su frustración emocional, sufre una crisis al comprender que es inmaduro e inseguro y lo lamenta amargamente. Este señor Doran es de mejor estrato so- cial que Poly Mooney. Es devoto y cumple regularmente con sus deberes religiosos, y además, es trabajador. Esa es la razón por lo que lucha internamente con su obligación de hombre de honor en su relación con una mujer, cuyo padre es un hombre despreciable, y cuya madre posee una casa de huéspedes de bien conocida dudosa reputación. Su desilución está acentuada por el hecho de que Polly es vulgar, low-class, y que hasta comete errores graves al hablar, tales como "séase y me han escrebido" (D 68).

Los comentarios burlescos de sus amigos en relación con el matrimonio eran realmente difíciles de aceptar; podía imaginárselos comentando el asunto a carcajadas" $(D, 68)$ (Subrayado mío). Doran, en su inmadurez, no obstante tiene la impresión de que los Mooneys "\%o habian atrapado" ( $D$, 68) (Subrayado mío), pero no hace nada para evitarlo. Existe también el temor al hermano de la mujer, Jack Mooney, su futuro cuñado. Recordaba el incidente que una vez presenció, cuando un artiste se pasó con la joven, y entonces Jack amenazó a los invitados diciendo que "...si alguien se atrevía a jugar esa clase de juego con su hermana, él le iba a hacer tragar los dientes: de seguro" (D, 70). Este temor físico es otro elemento que contribuye a que sienta que él [Doran] no vale nada. De esta forma vivirá toda su vida: es un hombre débil e incapaz de superar todo esto.

En la historia "Duplicados", el personaje frustrado es el señor Farrington, un apuesto y fuerte hombre, que vive bajo la presión de su irascible jefe, el señor Alleyne, así como en una situación de pobreza familiar. Este señor Farrington busca su escape en la bebida y para ello pide dinero prestado. La acción de otros personajes acentúa el desencanto de este hombre: no es un buen empleado y trata de escapar de sus deberes, lo que lógicamente le atrae la antipatía de su jefe, un hombrecito insignificante, opuesto a la alta estatura de Farrington.

La oficina es el punto de partida de las frustraciones de este señor Farrington; dos de las copias que debe hacer no están, porque aún no las ha hecho. Su trabajo es hacer copias manuscritas de documentos legales, ya que a principio de siglo, las copias hechas a máquina no se aceptaban como valederas legalmente. En relación con los duplicados que no aparecen, el señor Farrington le dice al señor Alleyne que ya las ha hecho y que "no sabe nada $(Q, 94)$ (Subrayado mío). Esta respuesta insolente exaspera al $\mathrm{Sr}$. Alleyne, quien delante de la 
señorita Delacour, una simpática cliente de la oficina, que ha presenciado todo, le dice a Farrington:

- iSo impertinente! iSo rufián! iLe voy a dar una lección! iVa a saber lo que es bueno! iSe excusa usted por su impertinencia o queda despedido al instante! iO se larga usted, ¿me oye?, o me pide usted perdón! (D, 94).

No solamente lo humilla e insulta al llamarlo rufián, sino que lo obliga a pedir perdón, enfrente de la dama y de sus compañeros de trabajo. No puede darse el lujo de renunciar a su trabajo dado que tiene responsabilidades en la casa, además de la falta de oportunidades en Dublín.

Después del trabajo, visita una cantina, Mulligan, en la calle Foolberg. Allí se encuentra con sus amigos, y con un matón inglés, un artiste del music-hall, llamado Weathers, mucho más joven que él. Este hombre alardea mostrando sus biceps a la gente, "y se jactaba tanto que los otros... Ilamaron a Farrington para que defendiera el honor nacional" $(D, 98)$. Esto da lugar a una demostración y en un juego de pulsos, Farrington es derrotado en menos de treinta segundos. Aumenta la humillación y "su cara color de vino tinto se [pone] más tinta de humillación y de rabia al haber sido derrotado por aquel mocoso" ( $Q$, 98) (Subrayado mío). Farrington acusa a su contrario de no jugar limpio; de nuevo se enfrentan, Farrington pierde una vez más. Desaparece así su prestigio enfrente de sus camaradas, entonces se retira: "un hombre con cara de pocos amigos [espera] en la esquina del puente O'Connell el tranvía que lo [lleve] a casa" $(\mathbb{Q}$, 99). Toda esta presión interna en el hombre debe salirle de algún modo, y el chivo expiatorio va a ser su pequeño hijo Tom; a quien da una paliza con un bastón, ya que no le tiene su comida lista y ha dejado que el fuego se apague. A pesar de todo, Farrington no se va a librar de toda su gran frustración, pues ésta lo acompañará en tanto que sea un mal trabajador, un matón con sus amigos y un padre miserable con sus hijos.

Finalmente tenemos algunos protagonistas cuyas personalidades son muy débiles y se encuentran bajo extremos de tensión y compulsión. Sus frustráciones los obligan a sumergir sus preocupaciones en los extremos más profundos de sus mentes; sienten lástima de sí mismos, reaccionan violentamente, o simplemente no hacen nada. En otras palabras, su yo interno se anula y es así abrumado por la acción de los otros.

Algunos de los protagonistas antes mencionados, podrían ser retomados bajo esta rúbrica, pero preferimos no ser muy reiterativos, por lo tanto en esta cuarta sección vamos a estudiar al pequeño Chandler, como ejemplo del más patético y sobresaliente caso de anulamiento de personalidad.

El cuento corto "Una nubecilla" presenta la historia del señor Tomás Chandler, quien es un humilde hombrecito, que ha fracasado aparatosamente como escritor. Su contraparte es su próspero amigo, el señor Ignacio Gallaher. El pequeño Chandler sufre también la opresión que la furia maternal de su castradora esposa ejerce constantemente sobre él.

En relación con el título de "Una nubecilla", David Weir nos comenta que:

los críticos han propuesto una serie de respuestas, pero ninguna de ellas enteramente satisfactoria. La nubecilla ha sido considerada como el mismo pequeño Chandler, empujada por el aeólico viento de Gallaher, un Gallaher abrumador; o por la esposa, obnubilando la vida de su esposo $^{43}$.

Zack Bowen está de acuerdo con William Tinall York en que es probable que la referencia esté relacionada con Reyes 1, 18,44, donde "El ías hace llover para aliviar la sequía de una tierra desgastada moral y literalmente... El primer signo es una nubecilla" (Subyarado mío) ${ }^{44-}$

Esta es una de las historias más bellas de Dublineses. James Joyce, mientras vivía en Roma, escribió a su hermano Estanislao una carta fechada el 18 de octubre de 1906, en que le dice: "Una página de 'Una nubecilla' me da más placer que todos mis versos" (Cartas, II, 182). En la historia, el pequeño Chandler e Ignacio Gallaher son dos personajes opuestos, como el día y la noche; Gallaher representa todo lo que el pequeño Chandler no es. Gallaher se fue a Inglaterra, en donde se convirtió en un periodista de mucho éxito. Representa un eco vivo de la voz de James Joyce "si uno [quiere] tener éxito, [tiene] que largarse" $(D, 76)$ de Irlanda. Gallaher es un homme raffiné, de maneras elegantes y con mucha experiencia. Chico Chandler, por el contrario, es un hombrecito manso, un poeta frustrado que sueña despierto con su éxito, gracias a la supuesta y futura recomendación de Gallaher para los editores de Londres.

Es evidente que Tomás Chandler tiene un fuerte complejo de inferioridad, y siempre está a la defensiva de la gente y de los lugares. El autor nos dice que "[escoge] las calles más tortuosas y oscuras y, el silencio que se [esparce] alrededor de sus pasos lo [perturba], como lo [turba] toda figura silenciosa y vagabunda; a veces el sonido de una risa baja y 
fugitiva lo [hace] temblar como una hoja" $(\supset, 75)$. $\mathrm{Ha}$ de reunirse con Gallaher en un exclusivo pub, llamado Coreless's, donde los empleados hablan lenguas extranjeras. Ir a un sitio de esos lo preocupa, ya que solamente gente refinada va allí, generalmente después del teatro, a comer ostras y tomar liqueurs. Se percata de esto una noche en que pasó y vio cuán ricamente iban ataviadas las damas y sus compañeros cuando entraban allí. Cuando se acerca al establecimiento, su agitación lo domina, y sus pasos son torpes e indecisos a la entrada de Coreless's, "el bar parecía estar lleno de gente y sintió que la gente lo observaba con curiosidad" $(0,77)$.

$\mathrm{Su}$ encuentro con Gallaher no es precisamente lo que él esperaba; su descarada mundanalidad lo impresiona al principio, pues contrasta con su provincialismo, la naiveté de su conversación y sus preguntas en contraposición a las respuestas de Gallaher. Chandler no ha viajado y sigue siendo un devoto ignorante de un mundo que gira más allá de Irlanda; de lo que está de moda y de los vicios de actualidad en el continente. Siente "en lo vivo el contraste entre su vida y la de su amigo, y le [parece] injusto. Gallaher [está] por debajo suyo en cuanto a cuna y cultura" $(D, 83)$.

Chico Chandler invita a Ignacio Gallaher a venir a casa, pero éste se excusa gentilmente, diciendo que está visitando Irlanda con otro amigo, y que tienen ya planes para ir a una fiesta a jugar cartas. Bajo parole d'honneur $(D, 82)$, promete que lo visitará el año próximo si vuelve a Irlanda.

Por un momento, Chico Chandler tiene un sentimiento de orgullo, y piensa que "[sabe] que [puede] hacer cualquier cosa mejor de lo que lo [hace] o haría nunca su amigo, algo superior al mero periodismo pedestre, con tal de que le dieran una oportunidad" 45 . Pero esta reflexión es solamente temporal, porque se da cuenta de que su timidez le impide su propio desarrollo, y que tiene que existir algo que lo "[reivindique] de alguna forma" que "[haga] valer su virilidad" $(D, 83)$. Con estas palabras acepta que otros lo hacen sentirse inferior, no deja, en verdad, de ser pequeño en cuerpo y alma.

Si Ignacio Gallaher lo hace sentirse miserable, después de que llega a casa, su esposa lo pone aún peor. Fácilmente podemos recrearlo en su estancia, cuidando de su niño, mientras ella sale a comprar algo. En este momento, un corriente de pensamiento fluye por su mente al meditar sobre su vida, en tanto que mira a la foto de su mujer, Annie. Se pregunta por qué tenía que casarse con esos fríos ojos de la fotografía. Su relación con ella no es del todo feliz. La esposa es de temperamento fuerte, agresiva y difícil de complacer. Medita en la agonía que tuvo que pasar para comprarle una blusa -ya que él considera impropio comprar prendas femeninas - para finalmente verla lanzar el artículo sobre la mesa en una racha de furia al saber que era muy caro. Mientras todo esto sucede, el niño comienza a llorar sin control. De pronto la mujer entra en la habitación y,

sin prestarle atención, ella comenzó a caminar por el cuarto, apretando al niño en sus brazos y murmurando:

- iMi hombrecito! iMi muchachito! ¿Te asustaron, amor?...

iVaya, vaya, amor! iVaya! ... iCosita! iCorderito divino de mamá! ... iVaya, Vaya! $(D, 87-8)$

(Subrayado mio).

La mujer llama al niño corderito, pero en el texto original, Joyce usa una palabra lambabaum, que en el dialecto irlandés equivale a lamb-baby, lambbaby, es decir, niño-cordero. También en el original la mujer usa otra expresión lamb of the world, o cordero del mundo, que contrasta con el epíteto que Jaun el Bautista usa para Jesús, que es el Cordero de Dios (Juan, 1, 29); (cf.: la respuesta de Jesús a Pilatos: "Mi Reino no es de este mundo" (Juan, 18, 36) ${ }^{46-}$

Inmediatamente después de la escena, Chicho Chandler se da cuenta por medio de una epifanía de que "[está] condenado a cadena perpetua" $(D$, 87 ), de que es muy poco, muy pequeño en su fuero interno, que "ha escogido una casita, una esposita, y una vidita" 47

Tomás Chandler está aniquilado, anulado por todos los que viven a su alrededor y su consuelo es llorar silenciosamente, ya que no tiene siquiera el valor de hacerlo con fuerza.

$\mathrm{Al}$ analizar todos estos aspectos de la vida de algunos de los personajes más importantes de $D u$ blineses, hemos hurgado en el fuero interno de ellos, para así demostrar cómo el elemento de las frustraciones es un hilo invisible, pero omnipresente, que une toda esta madeja que James Joyce tejió alrededor de los protagonistas de sus cuentos cortos, y que no es otra cosa que la constante desilusión del hombre de las calles de Dublín.

\section{NOTAS}

( 1.) James Joyce, James Joyce: Escritos crfticos, Introducción de Ellsworth Mason y Richard Ellmann, Trad. Andrés Bosch (Madrid: Alianza Editorial, 1975), p.9. 
(2.) Raúl H. Castagnino, El análisis literario (Buenos Aires: Editorial Nova, 1973), p.89.

( 3.) James Joyce, Dubliners (England: Richard Clay, Ltd., 1983), p.45. Para la versión castellana usaremos la traducción de Guillermo Cabrera Infante: James Joyce, Dublineses (Barcelona: Editorial Lumen), p.51. Todas las futuras referencias a este libro se harán sobre la misma edición y se indicarán en el texto entre paréntesis con la abreviación $D$ seguida de los números de página. Cuando se haga la traducción directamente del inglés se indicará con su correspondiente nota.

(4.) Florence, L. Walzl, "The Life Chronology of Dubliners," James Joyce Quarterly, 14, No.4 (1977), p.412.

(5.) Ibid., p.412.

(6.) James Joyce, Letters of James Joyce, Vol.I. ed. Stuart Gilbert (New York: Viking Press, 1957); reissued with corrections 1966 . Vols, II and III . ed. Richard Ellmann (New York: Viking Press, 1966), p.61. Todas las futuras referencias se harån sobre las mismas ediciones y se indicarán en el texto entre paréntesis con la palabra Carta, seguida del volumen y el número de página. Todos los textos están traducidos libremente por $\mathrm{F}$. Hernández $\mathrm{M}$.

(7.) William Powell Jones, James Joyce and the Common Reader (Norman, Oklahoma: University of Oklahoma Press, 1966), p.15. Traducción libre de F. Hernández.

( 8.) Don Gifford, Joyce Annotated (Los Angeles: The University of California Press, 1982), p.34. Traducción libre.

(9.) Esta cita ha sido traducida directamente del texto inglés sin seguir a Cabrera Infante. James Joyce, Dubliners A triad Panther Book (Sulffolk, England: Richard Clay Ltd., 1983), p.58.

(10). Zack Bowen, "Joyce's Prphilactic Paralysis", James Joyce Quarterly, 19, No.3 (1982), p.264.

(11) Esta cita ha sido traducida directamente del texto inglés sin seguir el de Cabrera Infante, p. 56.

(12) Nathan Halper, "The Life Chronology of Dubliners," James Joyce Quaterly, 16, No. 4 (1979), p. 476.

(13) Walzl, p. 412.

(14) Ibib., p. 412.

(15) Jones, pp. 108-9.

(16) Esta cita ha sido traducida directamente del texto inglés sin seguir el de Cabrera Infante, p. 101.

(17) Ellmann, Tindall, Levin.
(18) Patricia Kieckheffer, "Maria's Plants in 'Clay'," James Joyce Quarterly, 11, No. 1 (1973), p. 56.

(19) Esta cita ha sido traducida directamente del texto inglés sin seguir el de Cabrera Infante, p. 92.

(20) Esta cita ha sido traducida directamente del texto inglés sin seguir el de Cabrera Infante,p. 92.

(21) Albert J. Solomon, "The Mysteries of Hymeneal Future," James Joyce Quarterly, 17, No. 3 (1980). p. 304.

(22) M. Hubert McDermott, "'Clay' and Clê in Dubliners".James Joyce Quarterly, 20, No.2 (1983), p.227.

(23) El texto en inglés dice que María dormirá solamente en brazos de un caballero, que es la muerte; pero la muerte es una dama en español, por lo tanto se omite del texto.

(24) Salombn, p.305.

(25) Walzl, p.413.

(26) Esta cita ha sido traducida directamente del texto inglês sin seguir el de Cabrera Infante, p.46.

(27) Esta cita ha sido traducida directamente del texto inglés sin seguir el de Cabrera Infante, p.48.

(28) Edmund L. Epstein, "Hidden Imagery in James Joyce's 'Two Gallants'." James Joyce Quarterly, 7. No $4,(1970)$ pp. 369-70.

(29) La palabra epifanía, que viene del griego ' $\varepsilon \pi \iota \Phi \alpha \nu \varepsilon \alpha$ significa revelación. En el drama griego es el equivalente al momento deus est machina, cuando un dios aparece e impone el orden en la escena frente a él. En la tradición cristiana, la Fiesta de la Epifania es la revelación de la divinidad de Cristo a los Reyes Magos. James Joyce relaciona el tếrmino en forma muy especial. En la teorfa del arte en que Joyce trabajaba allå por el año de 1904, emplea este término de epifanía para los momentos en los cuales las cosas o la gente en el mundo revelan su verdadero valor o su esencia. Francesca Romana Paci, James Joyce (Barcelona: Ediciones Península, 1978), p. 139.

(30) Bowen, p. 184.

(31) Romana Paci, p. 184.

(32) Stanislaus Joyce, My Brother's keeper (New York: Viking Press, 1958), p. 62. Traducción libre de F. Hernández.

(33) Walzl, p. 392.

(34) Bowen, p. 184. 
(35) Eileen Kennedy, "Lying Still: Another Look at 'The Sisters'," James Joyce Quarterly, 12, No. 4, (1975), p. 362.

(36) Florence L. Walzl, "Joyce's: 'The Sisters': A Development," James Joyce Quarterly, 10, No. 4, (1973), p. 397.

(37) Ibid., p. 396.

(38) Ibid., p. 393.

(39) Ibid., p. 393. La Dra. Walzl considera este mismo punto sobre el mismo significado de la palabra queer, en este artículo.

(40) Walzl, p. 397.

(41) Castagnino, p. 123.

(42) Gifford, p. 40.

(43) David Weir, "'A Little Cloud': New Light on the Title", James Joyce Quarterly, 17, No. 3 (1980), p. 301.

(44) Bowen, p. 264.

(45) Esta cita ha sido traducida directamente del texto inglês sin seguir el de Cabrera Infante, p. 73.

(46) Gifford, p. 73.

(47) Walzl, p. 413.

\section{BIBLIOGRAFIA}

\section{FUENTES PRIMARIAS}

Ellmann, Richard. James Joyce. New York: Oxford University Press, 1959.

Joyce, James. The Critical Writings of James Joy$c e$, ed. Ellsworth Mason and Riahcrd Ellmann. New York: Viking Press, 1959.

James Joyce: escritos críuticos, Introd. y selección de Ellworth Mason y Richard Ellmann. Madrid: El libro de Bolsillo de Alianza Editorial, 1959.

. Dubliners. A Triad Panther Book. Suffolk, England: Richard Clay Ltd., 1983.

- Dublineses, Trad. Guillermo Cabrera Infante. Barcelona: Editorial Lumen, 1972.
. Dublineses, Trad. Guillermo Cabrera Infante. Barcelona: Editorial Lumen, 1972.

. Dubliners": Text, Criticism and Notes, ed. Robert Scholes and A. Walton Litz. New York: Viking Press, 1969.

. Letters of James Joyce. Vol. I, ed. Stuart Gilbert. New York: Viking Press, 1957; reissued with correction 1965. Vols. II and III, ed. Richard Ellmann, New York: Viking Press, 1966.

Joyce, Stanislaus. My Brother's Keeper. James Joyce's Early Years. New York: The Viking Press, 1958.

\section{FUENTES SECUNDARIAS}

Aquino, Santo Tomás de. Suma Teológica. Madrid: Biblioteca de Autores Cristianos, 1947.

Bidwell, Bruce and Linda Heffer. The Joycean Way. Baltimore, Maryland: The John Hopkins University Press, 1982.

Bowen, Zack. "Joyce's Prophilactic Paralysis. Exposure in Dubliners." James Joyce Quarterly, $19 \mathrm{~N}^{0} 3$ (1982), 257-273.

Burgess, Anthony. Joysprick; An Introduction to the Language of James Joyce. New York: Harcourt Brace Jovanovich, 1975.

. Rejoyce. New York: Ballantine Books, 1966. Castagnino, Raúl H. El análisis literario: introducción metodológica a un estilistica integra. Buenos Aires: Editorial Nova, 1973.

Curran, Constantin P. James Joyce Remembered. London: Oxford University Press, 1968.

Epstein, Edmund L. "Hidden Imagery in James Joyce's Two Gallants". James Joyce Quarterly, 7, NO4 (1970), 369-70

Ghiselin, Brewster. "The Unity of Joyce's Dubliners. Accent, 16, No2, (1966), 75-213.

Gicquel, Beranrd. El comentario de textos y la disertación. Barcelona: Oikos-Tau, S.A., 1982. 
Gifford, Don. Joyce Annotated: Notes for Dubliners and $A$ Portrait of the Artist as a Young Man. Lons Angeles: University of California Press, 1982.

Gross, John. Joyce. Barcelona: Ediciones Grijalbo, S.A., 1974.

Helper, Nathan. "The Life Chronology of Dubliners (II)". James Joyce Quarterly, 16, No4 (1979), 473-77.

Hart Clive. James Joyce's Dubliners: Critical Essays. New York: Faber and Faber, 1966.

Jones, David E. “Approaches to Dubliners: Joyce's James Joyce Quarterly, 15, No2 (1978), 108-117.

Jungmann, S.R., P. José A. El sacrificio de la misa. Tratado litúrgico. Madrid: Biblioteca de Autores Cristianos.

Kayser, Wolfang. Interpretación y análisis de la obra literaria. Madrid: Editorial Gredos, S.A. 1970.

Kennedy, Eileen. "Lying Still: Another Look at 'The Sisters'." James Joyce Quarterly, 12, № 4 (1975), 362-370.

Kibodeaux, R. Bruce. "Counterparts-Dubliners Without End". James Joyce Quarterly, 14, N01 (1976), 87-92.

Kieckheffer, Patricia. "Maria's Plants in 'Clay'." James Joyce Quarterly, 11, N01 (1973), 55-7.
Levin, Harry. James Joyce. Introducción crítica. Mexico: Fondo de Cultura Económica, 1978.

McDermott, M. Hubert. " 'Clay' and Clé in Dubliners." James Joyce Quarterly, 20, No2 (1983), $227-8$

Paci, Francesa Romana. James Joyce and the Common Reader. Norman, Oklahoma: University of Oklahoma Press, 1966.

Power, Arthur. Conversations with James Joyce, ed. Clive Hart. Chicago: The University of Chicago Press, 1982.

Solomon, Albert J. "The Mysteries of Hymeneal Future: Tradition and Games in 'Clay'. "James Joyce Quarterly, 17, N03 (1980), 303-6.

Tindall, William York. A Reader's Guide to James Joyce. New York: Farrar, Straus and Giroux, 1978.

Walzl, Florence L. "The Life Chronology of Dubliners". James Joyce Quarterly, 14, N04 (1977), 408-15.

. "Joyce's: 'The Sisters': A Development". James Joyce Quarterly, 10, No4, (1973) 735-421.

Weir, David. "' A Little Cloud': New Light on the Title." James Joyce Quarterly, 17, No3 (1980) 301-2.

Wellek, René, and Austin Warren. Theory of Literature. Penguin Books, London: Cox and Wyman, Ltd., 1970. 